\title{
El profesional de la Educación Social y la competencia mediadora en el ámbito de las personas mayores
}

\author{
Belchí Romero, Gema ${ }^{1}$; Martínez de Miguel, Silvia ${ }^{2}$ y Escarbajal de Haro, Andrés ${ }^{3}$
}

Recibido: 13 de septiembre de 2017 / Aceptado: 23 de septiembre de 2017

Resumen. El trabajo que se presenta es un estudio realizado sobre la competencia de mediación del educador social en el ámbito de las personas mayores, basándose para ello en las voces de los sujetos protagonistas del ámbito: educadores sociales, técnicos que trabajan en los centros de atención a personas mayores, el propio colectivo de mayores de 65 años y los Colegios Profesionales de Educadores sociales. El método investigador seleccionado ha sido de carácter descriptivo, utilizando como instrumentos la entrevista semiestructurada, el grupo discusión y el cuestionario. Los principales resultados destacan la importancia de esta función competencial para el desempeño profesional del educador social en el ámbito de las personas mayores.

Palabras clave: Educación social; mediación; competencias; personas mayores; profesionalización.

\section{[en] The professional of Social Education and the mediating competence in the field of the elderly people}

\begin{abstract}
The work presented is a research about the competence mediation of social educator in the field of elderly people, particularly, using the voices of protagonists of the field: social educators, professionals workers of centers that attend elderly people, the own collective of people over 65 and older and Professional Colleges of Social Educators. The method of investigation selected has been a descriptive study using as instruments the semi-structurated interview, group of discussion and questionnaire. The main results confirm the relevance of this competency function for the professional action of the social educator in the field of elderly people.
\end{abstract}

Keywords: Social education; mediation; competences; elderly people; professionalization.

Sumario. 1. Introducción. 2. Fundamentos teóricos. 3. Método. 4. Discusión y conclusiones. 5. Referencias bibliográficas.

Cómo citar: Belchí Romero, Gema; Martínez de Miguel, Silvia y Escarbajal de Haro, Andrés (2017). "El profesional de la Educación social y la competencia mediadora en el ámbito de las personas mayores", en Mediaciones Sociales, 16, 155-175.

\footnotetext{
${ }^{1}$ Universidad de Murcia (España). gema.belchi@um.es

${ }^{2}$ Universidad de Murcia (España). silviana@um.es

${ }^{3}$ Universidad de Murcia (España). adeharo@um.es
} 


\section{Introducción}

El estudio que se presenta forma parte de una investigación de carácter más global que tiene como eje central el análisis de la figura profesional del educador social como profesional necesario en el trabajo en el ámbito de las personas mayores, fundamentalmente en los centros sociales y otras instituciones como los centros de día y residencias, a los que acude dicho colectivo, de la Región de Murcia. Se pretende con ello investigar la pertinencia, por necesaria, de la Educación Social y de sus profesionales en el área de las personas mayores en estas instituciones, revalorizándolos y dándoles mayor visibilidad en un ámbito en el que aún no se les considera del todo necesarios o, al menos no se les reconoce como tal, remarcando que son un gran recurso en ese ámbito de las personas mayores, colectivo que cada vez es más numeroso.

De manera particular, el presente artículo aborda una de las competencias claves del educador social y que, actualmente cobra mayor relevancia y sentido, la competencia mediadora, teniendo como objetivo poner de manifiesto la importancia de la mediación en este colectivo. Para ello se hará un breve recorrido por el estudio realizado, abordando en una primera instancia los fundamentos teóricos para, una vez realizado lo anterior, especificar el proceso de la investigación: el método, los participantes implicados, los instrumentos utilizados, el procedimiento, los resultados y las conclusiones.

Para el desarrollo del estudio se establecieron los siguientes objetivos:

- Identificar la importancia que ofrece la acción mediadora en el ámbito de las personas mayores.

- Analizar las atribuciones y acciones profesionales desarrolladas por los educadores sociales.

\section{Fundamentos teóricos}

\subsection{El papel de la competencia mediadora de los educadores sociales con el colectivo de personas mayores}

Mucho se ha oído hablar y se ha escrito acerca de la mediación en los últimos años, de su necesidad, su repercusión, su puesta en escena, su praxis... pero ¿qué es la mediación? Es necesario, antes de adentrarse en el grueso de este trabajo, explicar brevemente qué es eso de la mediación, sin pretender con ello hacer un estudio exhaustivo al respecto, pero sí una contextualización en el ámbito seleccionado de investigación.

La mediación es entendida como un proceso, ya que tiene principio y fin, en el que un tercero interviene ocupando un lugar de cierto poder, pero renuncia a hacer uso de ello, manteniendo una ética e integridad que impida hacer juicios de valor y opiniones respecto a los acuerdos a los que haga llegar a los participantes en la mediación (Málik, y Herraz, 2005). Pero entonces, ¿qué hace el mediador? El mediador se dedica a llevar el control del proceso, que es lo que los clientes necesitan, dejando a ellos la elección de los contenidos a tratar, las alternativas y 
soluciones, manteniéndose neutral e imparcial en todo momento. Por tanto, la mediación parte del conflicto, de la disputa, de situaciones disruptivas a las que dar solución. Es, por consiguiente, un recurso preventivo a disposición de los profesionales que trabajan en el campo socioeducativo, que se sitúa entre el compromiso y la colaboración. Entre sus objetivos cabe resaltar la contribución a generar un clima que fomente la convivencia y las actitudes cooperativas. Siguiendo, para ello, una serie de normas de funcionamiento sobre las que tienen que estar de acuerdo todas las partes implicadas y, además, debe planificarse con el fin de conseguir los objetivos previstos. Todos los implicados tienen que estar informados de los mismos, de lo que es la mediación y de sus características, con el fin de que cada uno sea protagonista en la resolución del conflicto (Pérez de Guzmán, 2008).

Por su parte, Bermúdez, Prats y Uribe (2000) definen la mediación como un recurso al alcance de personas, que actúa como puente, con el fin de promover un cambio constructivo en las relaciones entre ellas, actuando por consiguiente la mediación como un elemento preventivo. Del mismo modo, favorece el reconocimiento del otro como diferente, el acercamiento entre las partes, la comunicación y la comprensión mutua, el aprendizaje y el desarrollo de la convivencia, la búsqueda de estrategias alternativas para la resolución de conflictos y la participación comunitaria. Desempeñando por ello un papel importante en pos de la resolución de conflictos, dado que propicia la evolución y sustitución de intervenciones paternalistas por las de implicación y protagonismo de las personas participantes. Por tanto, los pilares sobre los que se asienta son: la participación, el protagonismo de las partes, la no delegación de poder en terceros ajenos al marco del conflicto y la toma de decisiones autónomas. Todo aquello en lo que un educador social tiene competencia en el ámbito de las personas mayores.

La profesión de educador social, en la actualidad posiblemente aún se encuentre en su etapa de 'adolescencia', aunque parece haber alcanzado la necesaria legitimidad social y comenzando a elaborar un saber propio, a partir de un conocimiento que en su origen fue básicamente empírico. No obstante, hay que reconocer que, en este como en otros ámbitos, la construcción de un nuevo campo profesional es un proceso lento y difícil. Lo que parece estar claro, son los elementos sustanciales que la definen. El Consejo General de Colegios de Educadores y Educadoras sociales, en su documento de profesionalización (2007), establecía la definición de este profesional como:

Derecho de la ciudadanía que se concreta en el reconocimiento de una profesión de carácter pedagógico, generadora de contextos educativos y acciones mediadoras y formativas que son ámbito de competencia profesional del educador social, posibilitando:

- La incorporación del sujeto de la educación a la diversidad de las redes sociales, entendida como el desarrollo de la sociabilidad y la circulación social

- La promoción cultural y social entendida como apertura a nuevas posibilidades de la adquisición de bienes culturales, que amplíen las perspectivas educativas, laborales, de ocio y participación social (p.12).

Los mediadores han existido siempre, tal como se indicaba en la Primera Conferencia de la Paz de la Haya, celebrada en 1899, donde en su artículo 4 señala: "el papel del mediador consiste en conciliar las reclamaciones antagónicas y 
apaciguar los sentimientos de agravio que puedan haber surgido entre los estados desavenidos". En EE UU, en torno a 1970, se vio la necesidad de buscar mecanismos que resolvieran los conflictos con independencia de los procesos judiciales, de un modo más rápido y económico, lo que hizo que este proceso se extendiera a diversos ámbitos sociales a través del perfil del mediador, conllevando que en la actualidad se haya constituido en una herramienta de gran valor en el ámbito socioeducativo en pos de la resolución de conflictos, teniendo como consecuencia que el educador social, como profesional formado en materia mediadora, cobre cada vez más importancia en contextos y situaciones susceptibles de mediación. Pero no sólo es importante que el educador social esté preparado técnicamente y conozca con precisión los pasos a seguir, sino que debe saber articular el proceso técnico de mediación y el conocimiento del contexto. Por tanto, no debe actuar sin haber realizado un análisis detallado de la realidad en la que se ha producido el conflicto, llegando a conocer toda la trama. Por lo que se hace imprescindible que este profesional conozca los patrones, normas y características culturales de las partes implicadas antes de iniciar el proceso de mediación, si desea alcanzar el éxito en dicho proceso.

Pero la mediación no es la panacea que pueda resolver todos los conflictos. Es preciso analizar qué aspectos son o no susceptibles de resolver a través de esta acción socioeducativa. Ante esta situación el educador social, desde una perspectiva integral e integradora, debe (Pérez de Guzmán, 2008):

- Partir del supuesto de que todos los implicados deben ganar.

- Planificar y diseñar una estrategia concreta. Tener claridad en lo que es o no importante y seleccionar la mejor alternativa para negociar.

- Crear un clima en el que se puedan expresar las partes con naturalidad, con el fin de hacer manifiesto lo latente y explícito lo implícito.

- Su ética debe regirse por el principio de la imparcialidad y la neutralidad.

- Acompañar en el proceso. Ponerse en el lugar del otro y entender su posición, lucha y sentimientos.

- Buscar la mejor solución teniendo en cuenta el bien común.

- Utilizar la capacidad de escucha, así como la retroalimentación. Dotar a las partes de recursos comunicativos de calidad para que puedan resolver el conflicto.

- Hacer aflorar los sentimientos de las partes con el fin de que todos se expresen. Sólo de este modo se podrá abordar el tema y evitar que persistan heridas y resentimientos.

El mediador debe otorgar la palabra a las partes y escucharlos activamente, evaluando si se podrán diseñar estrategias consensuadas para resolver el conflicto, a fin de conseguir aquello que necesitan y acompañarles en el proceso. No se puede identificar al mediador como el que resuelve conflictos, pues el mediador no tiene ningún poder de decisión, sólo orienta el proceso de negociación entre las partes, tratando de llegar a un acuerdo que beneficie a ambas, mostrándose imparcial y neutral ante el conflicto y las partes, lo que hace fundamental e ineludible un 
código deontológico que regule la conducta del educador social, y garantice así la profesionalidad, la integridad, la neutralidad y la imparcialidad. Tal y como afirman algunos autores (Málik, y Herraz, 2005; Pérez de Guzmán, 2008), este tipo de método es cada vez más demandado, presentándose el educador social como uno de los profesionales más capacitados, por lo que la solicitud de mediación a profesionales de la Educación Social es recurrente, debido a que desempeñan su labor en contextos socioeducativos, en los que el conflicto suele generarse con asiduidad, siendo los ámbitos muy diversos, lo que supone que el rol del educador-mediador sea flexible, adaptándose a las necesidades contextuales, lo que dificulta la definición de un perfil profesional específico. Los roles profesionales que desempeña el profesional de la Educación Social son muy diversos, pues el perfil del educador social es un perfil profesionalizador amplio e importante. Pero, centrado en el objeto de estudio de este trabajo referido a su concreción en el ámbito de las personas mayores, el perfil que debe caracterizar al educador social es el de ser un profesional de la educación que trabaja en la intervención directa sobre los recursos y mediaciones tendentes a conseguir una adecuada y plena integración social del colectivo de personas mayores. Siendo su principal función la cantidad de atención que presta a lo que le dicen estas personas, a sus necesidades de relación, a los procesos comunicativos a establecer, a la posibilidad de compartir experiencias; en lugar de centrarse en la cantidad de información que deba ofrecer (Martínez de Miguel, Escarbajal de Haro y Salmerón, 2016), estando su competencia mediadora a la orden del día en el colectivo de personas mayores.

Por tanto, es posible identificar una serie de competencias comunes a todos los ámbitos de intervención. Todas las definiciones tienen en común que una competencia implica hacer algo en concreto, no es sólo pensar ni sólo saber, más bien es un proceso de articulación de los recursos y las capacidades que se poseen frente a un contexto y situación determinados. Por ello, toda profesión debe ser consciente de que su supervivencia como ocupación depende, en buena medida, de la destreza que muestre en hacer surgir y mantener la creencia pública en que las competencias ofrecidas les son necesarias a la población. Y de modo concreto, la Asociación Española de Educadores Sociales (ASEDES), establece las funciones y competencias propias de este perfil profesional. Llama funciones profesionales a aquellas que forman parte del campo de responsabilidad del profesional de la Educación Social en un marco de actuación definido y que se encuentran en relación directa con las acciones y actividades correspondientes a los niveles formativos de estudio universitario y/o asumido por la formación o experiencia. Dichas acciones y actividades se engloban atendiendo al nivel de particularidad y especificidad del profesional que las pone en marcha, las sostiene y da cuenta de ellas.

Estas funciones de las que habla están caracterizadas por responsabilidades acogedoras y delimitadoras. Son acogedoras porque se orientan a incluir en la interacción a personas y/o colectivos reconocidas como sujetos de la educación, para promover procesos de cambio que posibiliten su desarrollo cultural y/o educativo. Y delimitadoras porque buscan el establecimiento de acuerdos, compromisos y límites (ASEDES, 2007). Las tres primeras funciones se refieren a la práctica socioeducativa (Transmisión, formación, desarrollo y promoción de la 
cultura; Generación de redes sociales, contextos, procesos y recursos educativos y sociales; Mediación social, cultural y educativa), diferenciando así el trabajo realizado por el educador social de otros profesionales presentes en el ámbito social. El resto de funciones (Conocimiento, análisis e investigación de los contextos sociales y educativos; Diseño, implementación y evaluación de programas y proyectos en cualquier contexto educativo; Gestión, dirección, coordinación y organización de instituciones y recursos educativos), aunque de manera diferente en cada profesional, pueden ser compartidas.

Centrando la atención en la función mediadora, ésta ha sido reconocida como propia de los educadores sociales por la Asociación Estatal de Educación Social (2007) como una de las seis indispensables en el ejercicio profesional. La formación para su desarrollo implica promover competencias basadas en: la comunicación interpersonal, el análisis de las posiciones enfrentadas y la evaluación del conflicto (Sánchez, 2013). Igualmente, Múgica (1991), estableció como una de las principales funciones de la Educación Social, comunes a todos los educadores sociales, la siguiente: "mediar entre los sujetos de la intervención y las instituciones, facilitando el acceso normalizado a los recursos (escolares, sociales, laborales, etc.), otorgando relevancia a esta competencia profesional" (p.77). En eta misma línea, el Centro de Orientación e Información de Empleo (COIE) de la Universidad de Murcia, a fecha de 2017, establece entre las ocupaciones del educador social en el sector privado, el sector público y el tercer sector la de mediador intercultural y familiar; afianzando aún más si cabe, la competencia mediadora al profesional de la Educación Social.

Sin embargo, de manera concreta existe poca literatura científica sobre acciones concretas de mediación en el ámbito de las personas mayores, pero ello no es óbice de desconsideración, sino todo lo contrario. Si se recoge uno de los significados que Cohen Emérique (1997: 9.) atribuye a este término: "intermediación en las diversas situaciones y circunstancias en las que aparecen dificultades y problemas de comunicación". Es decir, refleja la necesidad del educador de conocer los códigos culturales de los implicados para poder facilitar el acercamiento a un colectivo, tradicionalmente excluido tras la jubilación, a las diferentes dimensiones que hacen a la persona seguir vinculada a la sociedad, despojándola de su aureola inerte y estática, como ser humano capaza de seguir manteniendo las mismas capacidades y acciones que realizaba cuando ejercía su rol laboral. En ese sentido, pueden destacarse tres ámbitos principales en el trabajo de mediación con el colectivo de personas mayores (Martínez de Miguel y Escarbajal Frutos, 2009):

a) La mediación para la prevención, relacionándola también con la vulnerabilidad socioeconómica.

b) La mediación para la resolución de conflictos culturales.

c) La mediación para la creación de nuevas estrategias de relación e intervención entre diferentes colectivos, en los distintos ámbitos de contacto y relación social.

Naturalmente, para llevar a cabo una función de mediación el educador social deberá conocer a las partes implicadas, su cultura, inquietudes, dificultades y ofrecer un amplio abanico de posibilidades que beneficien a todos o al mayor 
número posible de implicados en condiciones de igualdad. De este modo podrán convertirse en agentes relevantes que favorezcan la transformación del colectivo, ofreciendo asimismo el protagonismo a los destinatarios de las acciones educativas tratando de promover procesos de comunicación que contribuyan a la búsqueda conjunta de alternativas (Martínez de Miguel y Escarbajal Frutos, 2009).

Como ejemplo práctico de mediación en el ámbito de mayores, hay una experiencia de 2007, a través del proyecto de investigación y desarrollo "MEDIMAYOR". Se trata de la mediación como instrumento de gestión de conflictos en el ámbito de las personas mayores autónomas y dependientes, cuyos resultados fueron muy positivos: el $95,5 \%$ de cuyos participantes recomendaría la mediación a otras personas. Además, se apunta que se consiguió cambiar las percepciones del conflicto entre los participantes, logrando una mayor seguridad en el enfrentamiento y que en aquellos casos donde no se llegó a alcanzar acuerdo, al menos mejoró la relación (Rueda, 2013). Pero hay escasa literatura científica, a través de proyectos de investigación concretos acerca de la mediación en el ámbito de las personas mayores, por lo que existe un escaso conocimiento y reconocimiento de todo los agentes intervinientes (personas mayores, profesionales y educadores sociales que trabajan en el ámbito) en relación a su relevancia en el trabajo socioeducativo.

No obstante lo anterior, las situaciones de mediación en el colectivo de personas mayores pueden ser muy diversas. En el ámbito familiar, existe una preocupación creciente sobre la reestructuración del hogar y de las familias que afectan considerablemente al entorno del mayor tras el azote de la crisis socioeconómica: retorno de hijos separados, cuidado de los nietos,..... A nivel social basta decir el gran distanciamiento comunicativo intergeneracional entre las jóvenes generaciones y las de mayores potenciado por la brecha digital. El incremento de población mayor procedente de otros países que pone de relieve otra necesidad añadida de índole cultural. A ello hay que sumar las situaciones conflictivas que por el contrario están generando el cuidado de las personas mayores dependientes por parte de sus familiares ante la toma de muchas de las decisiones. Y se podrían seguir planteando ejemplos, que ponen de manifiesto la importancia del trabajo educativo desde la óptica de la mediación.

De ahí que se pretenda realizar un trabajo de investigación para aproximarse a esta realidad. Este trabajo, como se indicó en la introducción, constituye una pequeña parte de una investigación mayor acerca de la profesionalización del educador social en el ámbito de las personas mayores, pero puede permitir analizar cuál es la situación actual al respecto, y así poder derivar a un nuevo reto investigador con mayor profundidad.

\section{Método}

Para llevar a cabo este trabajo se optó por un tipo de investigación aplicada de campo, de carácter exploratorio-descriptivo, utilizando una combinación mixta de técnicas metodológicas (cuestionario, entrevistas y grupos de discusión).

\subsection{Participantes}


Con el fin de obtener una visión amplia de los agentes intervinientes se toma en consideración las voces de los propios protagonistas; de un lado, personas mayores, trabajadores de los centros sociales de personas mayores del Instituto Murciano de Acción Social de la Región de Murcia, educadores sociales que desarrollan su labor profesional con el colectivo de personas mayores en instituciones públicas y privadas, y representantes del área de Envejecimiento de los Colegios Profesionales de Educadores Sociales. Finalmente, fueron un total de 112 participantes. Para la selección e inclusión de la muestra, se contactó con las corporaciones locales y municipales de la Región de Murcia en el área de personas mayores así como a través del Instituto Murciano de Acción Social, optando por un criterio no probabilístico e intencional, para lo cual se seleccionaron voluntariamente 69 personas mayores (realizando 6 grupos de discusión), 16 profesionales de los centros de mayores de la Región de Murcia, 21 educadores sociales que desarrollaban su labor educativa con el colectivo de personas y 6 representantes del área de Envejecimiento de Colegios Profesionales de Educadores Sociales.

Figura 1. Descripción de los participantes de la investigación

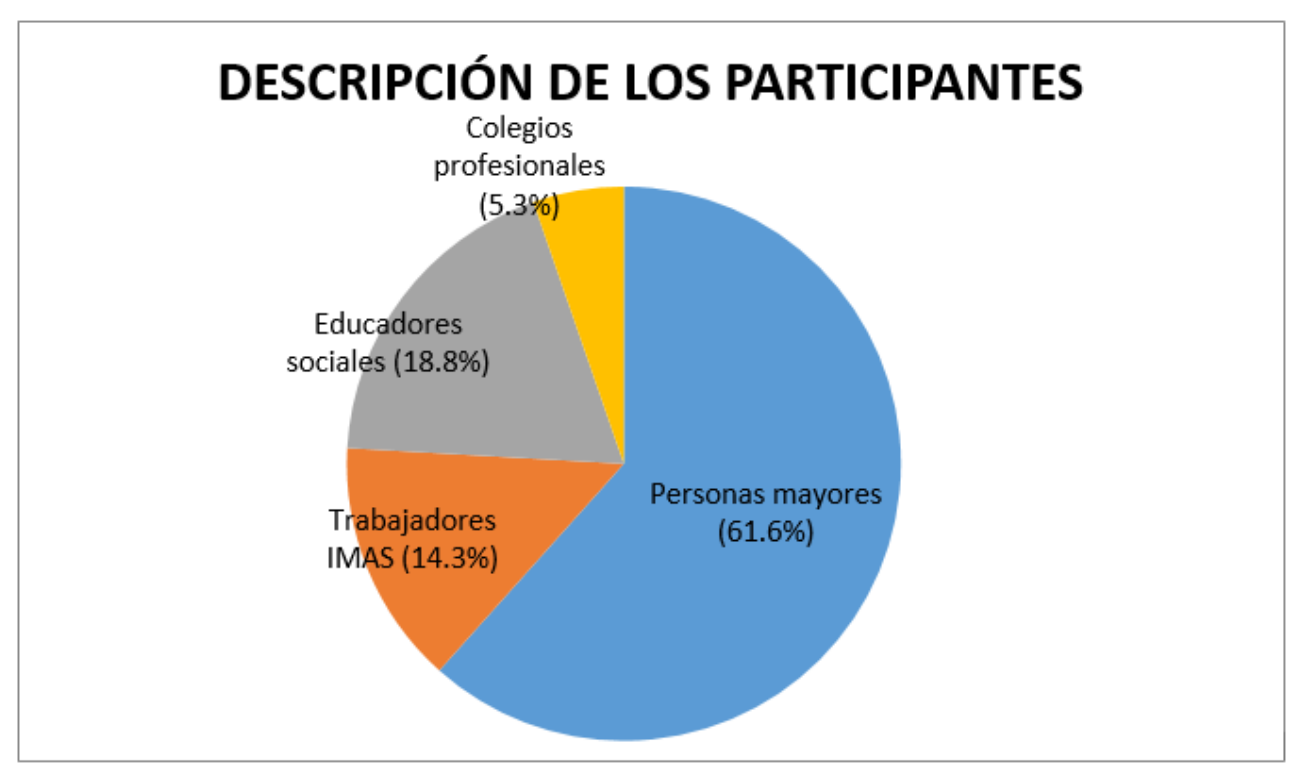

Fuente: elaboración propia. 


\subsection{Instrumentos}

El diseño de los instrumentos y técnicas para la puesta en contacto con la población participante obedece tanto a la naturaleza del contexto de la investigación como a los fenómenos de interacción y los hallazgos que se van dando en el proceso investigativo. En esta medida, el estudio demandaba el uso de algunas herramientas cualitativas y otras cuantitativas, con el fin de respetar las dinámicas de la población involucrada y responder a los objetivos planteados.

En cuanto a los instrumentos utilizados, fueron considerados, el cuestionario para los representantes de los Colegios Profesionales, la entrevista semiestructurada para educadores sociales y resto de profesionales y el grupo de discusión con el colectivo de personas mayores. Se consideraron las estrategias más adecuadas para cada grupo con el fin de recoger la información que se pretendía. En los Colegios Profesionales por las distancia geográfica constituía un recurso efectivo el envío del cuestionario vía correo electrónico, previo contacto telefónico. En cambio, se optó por entrevistas y grupos de discusión con los profesionales y personas mayores, respectivamente, de diferentes municipios de la Región de Murcia puesto que permite recoger y cualificar todo tipo de datos más allá de la mera descripción, e igualmente ayudan a mantener un contacto directo con ellas, intercambiando impresiones, opiniones, sentimientos y significados personales, siguiendo el modelo propuesto por Martínez de Miguel (2003). De acuerdo con Plannas, Pineda y Gil (2014), el uso de las estrategias participativas en la recogida de información permite obtener una visión común de los implicados acerca de su realidad. Y para el tipo de estudio y agentes implicados, se consideró muy pertinente.

\section{a. Procedimiento}

Las etapas seguidas en el proceso de investigación fueron las siguientes:

Para iniciar el trabajo de campo de la investigación, se procedió de la siguiente manera:

1. Diseño y validación de instrumentos.

2. Solicitud de permisos institucionales.

3. Selección discrecional de los informantes.

4. Envío de cuestionarios a los 17 Colegios Profesionales de Educadores Sociales del territorio español.

5. Desplazamiento de los investigadores hasta los centros donde se citó a las personas participantes del estudio para el desarrollo de entrevistas y grupos de discusión.

6. Transcripción en formato texto para el tratamiento y análisis de la información.

\section{b. Resultados}

Para proceder al análisis de resultados se utilizó el programa ATLAS.ti v7.5.13 en el caso de las entrevistas y los grupos de discusión, para realizar el tratamiento de 
la información, configuración de gráficos y creación de redes semánticas como recursos expositivos de los datos, a los que se une al texto narrativo como estrategia de exposición de los resultados; y, por otra parte, en el caso de los cuestionarios, con el paquete estadístico SPSS v. 22 para Windows.

Con el fin de obtener una visión clarificadora de los participantes se establecieron las siguientes categorías de análisis:

A) Importancia de la función mediadora en el ámbito de las personas mayores.

B) Identificación de la función mediadora en el educador social

C) Significado de la función mediadora

De manera general, se pueden observar las relaciones establecidas entre las categorías de análisis identificadas y los principales agentes participantes personas mayores, técnicos y educadores sociales. 


\section{Figura 2. Red semántica con las aportaciones de las personas mayores, técnicos y educadores sociales.}

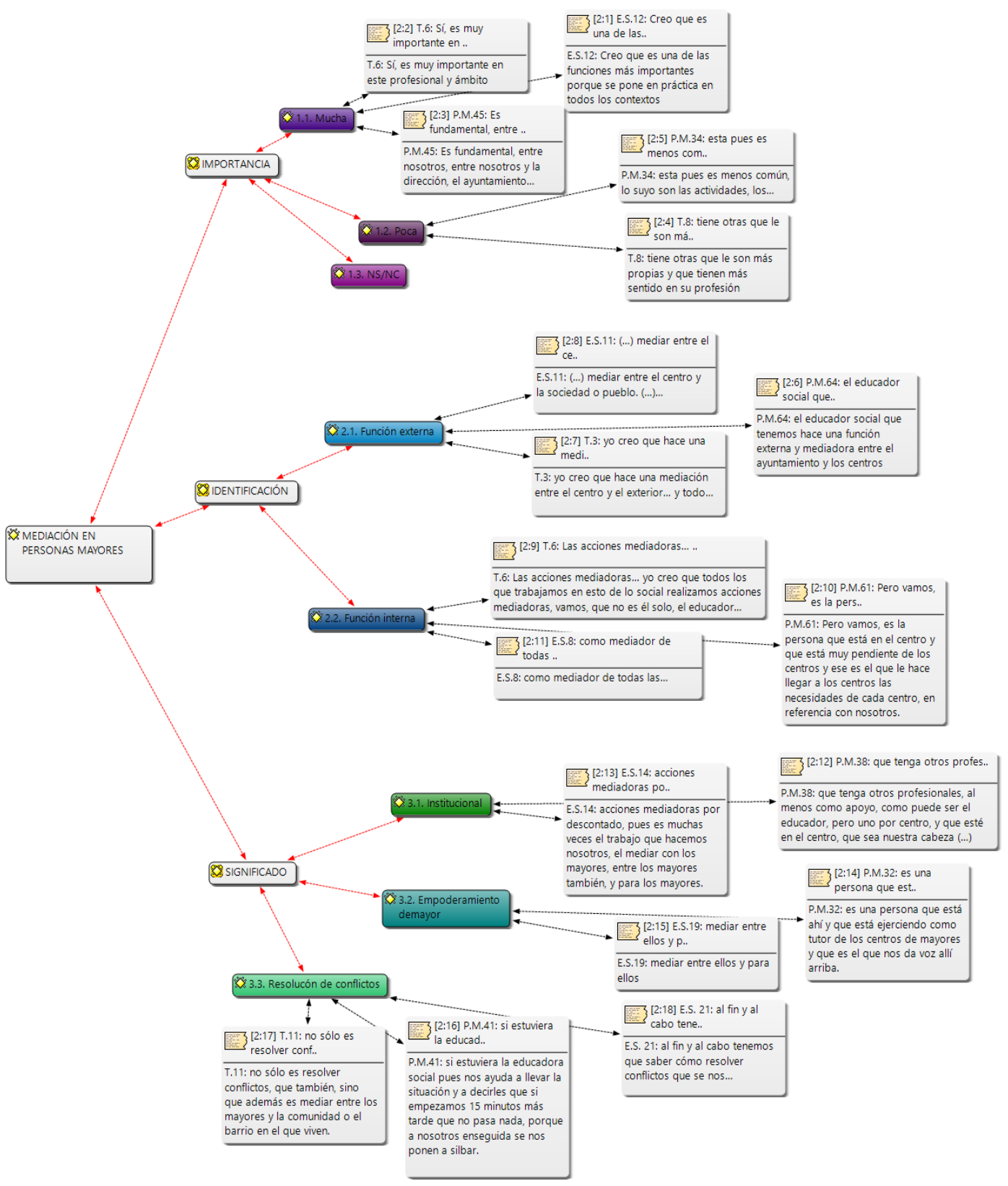

Fuente: elaboración propia 
De manera concreta, se procede a su pormenorización por categorías.

A) Importancia de la función mediadora en el ámbito de las personas mayores.

La primera categoría de análisis estaba referida a la necesidad de conocer como punto de partida del trabajo de investigación la relevancia que, en los participantes, tiene el educador social para el colectivo de personas mayores, y, como función esencial de su ejercicio profesional, la acción mediadora.

Por ello se hacía necesario abordar esta categoría. Mediante un ítem se preguntó a los participantes si consideraban relevante que el educador o educadora social ejercieran una función mediadora como elemento clave de su labor. Al respecto, la gran mayoría, un total de 92 personas (82.1\%), seguidas de 17 personas que no refieren discurso alguno en relación al tema (15.2\%), y un pequeño número, un total de 3, que dicen que la función mediadora no es tan importante en dicho ámbito ni clave del educador social (2.7\%).

\section{Figura 3. Importancia de la función mediadora en el ámbito de las personas mayores.}

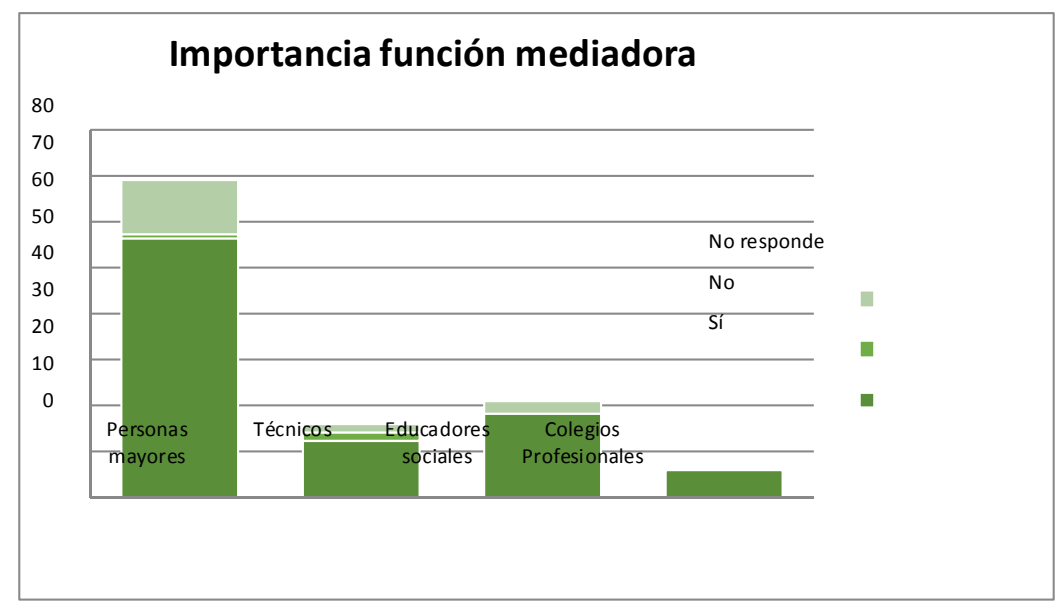

Fuente: elaboración propia.

Por lo que se observa en el gráfico, los participantes en la investigación consideran que es una acción relevante a desarrollar en quehacer profesional del educador social en el trabajo con este colectivo.

B) Identificación de la función mediadora en el educador social

Del mismo modo, además de otorgársele importancia a la función mediadora, también se buscó si ésta era identificada como característica del profesional de la Educación Social y de qué manera, es decir, se estableció un ítem para averiguar de 
qué manera identificaban los participantes esta función en consonancia con el educador social.

Así, con respecto al colectivo de mayores participantes hay que decir que presentan dificultades a la hora de identificar acciones concretas en las que perciban la función mediadora, quizá porque en muchos de sus centros no se encuentra este profesional en el organigrama de trabajadores. No obstante, un grupo minoritario de mayores $(26 \%)$ refirió en su discurso el papel mediador que ejerce el educador social, aludiendo al mismo de la siguiente manera:

Pues es la persona que está entre el ayuntamiento y los centros. Es digamos el que recoge de aquí de los centros y es el que le da paso al ayuntamiento para ver las inquietudes de cada centro y las necesidades de cada centro. Luego allí ya pues si lo ven o no lo ven es otra cosa. Pero vamos, es la persona que está en el centro y que está muy pendiente de los centros y ese es el que le hace llegar a los centros las necesidades de cada centro, en referencia con nosotros. (PM15); (...) es el que se lleva los guantazos nuestros y del ayuntamiento. Se los lleva por todos lados. (PM49); (...) el educador social que tenemos hace una función externa y mediadora entre el ayuntamiento y los centros. (PM64).

Por su parte, los técnicos entrevistados también presentan limitaciones a la hora de concretar las acciones mediadoras del educador social, aunque en una proporción menor ya que el $57 \%$ de los entrevistados se refiere en su discurso.: (...) pero por lo poco que sé pienso que sí, que su trabajo deriva en la mediación (...) (T4); No obstante, encuentran dificultades para diferenciar en ocasiones de su propio quehacer profesional, aunque se refirieron a ello en un porcentaje más significativo que en el colectivo de mayores: las acciones mediadoras... yo creo que todos los que trabajamos en esto de lo social realizamos acciones mediadoras, vamos, que no es él solo, el educador social, aunque sí que también es competencia porque el trabajo con personas siempre te lleva a mediar. (T16).

En cuanto a los educadores sociales en activo que trabajan con el colectivo de personas mayores, identifican claramente dicha función con sus competencias como se reflejan en las siguientes respuestas: (...) como mediador de todas las partes implicadas en el proceso de intervención. (ES8); (...) mediar entre el centro y la sociedad o pueblo. (...) actuaríamos de medidores del centro y la calle. (ES11).

Referente a los Colegios Profesionales, mediante un cuestionario se obtiene respuesta de seis de ellos: Cataluña, Región de Murcia, Islas Baleares, Extremadura, Castilla- La Mancha y Castilla y León, donde se aborda la función de mediación social, cultural y educativa en el ámbito de las personas mayores.

En una escala que comprende el intervalo 1 (poco propia del educador social) al 5 (muy propia del educador social) se hace una baremación de las competencias que engloba la función de mediación social, cultural y educativa según ASEDES (2007), obteniéndose una puntuación media por parte de los Colegios de un 4.1 y una desviación típica de 0.25 .

En la siguiente Figura (4) se muestra la distribución porcentual de los colegiados en relación a las respuestas ofrecidas con respecto a la identificación de 
la función de la acción mediadora en el educador social, pudiéndose observar equidad en las mismas: dos colegiados (Cataluña y Murcia) la identifican como muy propia del educador social (33.3\%), otros dos (Castilla-La Mancha e Islas Baleares) aluden que es bastante propia (33.3\%) y, los últimos dos (Castilla y León y Extremadura) manifiestan que es poco propia de sus competencias profesionales $(33.3 \%)$.

Figura 4. Distribución porcentual de los Colegios Profesionales en relación a la identificación de la función mediadora en el educador social.

\section{Función mediadora Colegios Profesionales}

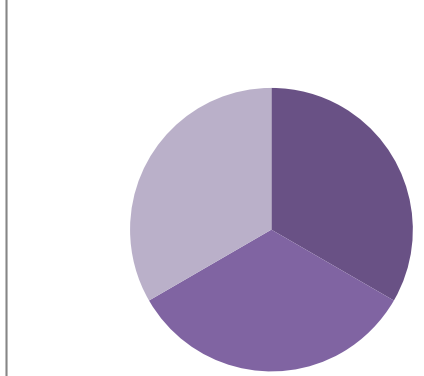

- Muy propia del ES (33.3\%)

Bastante propia del ES (33.3\%)

Poco propia del ES (33.3\%)

Fuente: elaboración propia.

Por lo que, si se suman los porcentajes de aquellos que aluden a la adecuación de la misma en su profesión, se observa que una es función muy relevante en el ejercicio profesional.

C) Significado de la función mediadora

La función mediadora no tiene un significado único, engloba tantas competencias como personas y contextos. De tal modo que será vista de una u otra forma según quién la defina y el contexto en que se encuentre. Esto es lo que se derivó de esta categoría, quedando de manifiesto la importancia que se le da a dicha competencia pero, a su vez, la multitud de acciones y significados que engloba en el ámbito de las personas mayores. Por lo expuesto, se estableció un ítem que englobaba la cuestión sobre qué suponía la mediación en sí abordada desde el perfil profesional del educador social.

A tenor de lo expuesto, en el caso de los propios mayores, no sólo reconocen la competencia como función del educador social, el cual media entre personas, instituciones $\mathrm{y} / \mathrm{u}$ organismos, sino que además se le atribuye, dentro de dicha 
competencia, la de representante de las personas mayores, viéndose este profesional como una figura que da lugar a que las personas de edad tengan voz y sea éste quien la abandere : si estuviera la educadora social pues nos ayuda a llevar la situación y a decirles que si empezamos 15 minutos más tarde que no pasa nada, porque a nosotros enseguida se nos ponen a silbar. (PM41); (...) que tenga otros profesionales, al menos como apoyo, como puede ser el educador, pero uno por centro, y que esté en el centro, que sea nuestra cabeza (...) es una persona que está ahí y que está ejerciendo como tutor de los centros de mayores y que es el que nos da voz allí arriba. (PM64).

Por su parte, los trabajadores de centros sociales de mayores aluden (en un porcentaje significativo) a la resolución de conflictos como función del educador social expresando al respecto lo siguiente: hace una mediación entre los mayores y los familiares, los mayores y otros profesionales, los mayores y los centros... (T2); (...) no sólo es resolver conflictos, que también, sino que además es mediar entre los mayores y la comunidad o el barrio en el que viven (...) (T11).

Los educadores sociales que trabajan con personas mayores identifican la acción mediadora, tanto para la resolución de conflictos como para la conciliación entre personas o para dar voz e intervenir por los propios mayores: mediación social, cultural y educativa. (ES7); (...) como mediador de todas las partes implicadas en el proceso de intervención. (ES8); (...) mediar social, cultural y educativamente. (ES11); (...) acciones mediadoras por descontado, pues es muchas veces el trabajo que hacemos nosotros, el mediar con los mayores, entre los mayores también, y para los mayores. (ES14); (...) ejerciendo de mediador en la resolución de conflictos. (ES18); (...) mediar entre ellos y para ellos. (ES19); (...) ser capaz de mediar en conflictos y para la resolución de problemas. (ES20); (...) al fin y al cabo tenemos que saber cómo resolver conflictos que se nos presentan en el día a día, y que todas las partes ganen. (ES21).

Los representantes de los Colegios Profesionales explicitan, dentro de la función de medicación, una serie de competencias que engloban la misma, otorgándole a dicha función varios significados.

Pormenorizando estas competencias que especifica ASEDES (2007), es observable que la que menor puntuación refiere es la C.1. (Conocimientos teóricos y metodológicos sobre mediación en sus diferentes acepciones), obteniendo un 3.7 de media, situándose así entre "poco propia del educador social" y "bastante propia del educador social". Extremadura es el que menos nota numérica expresa, con un 2 (muy poco propia), seguido de Castilla y León e Islas Baleares con un 3 (poco propia), tras ellos se encuentra Castilla- La Mancha, con un 4 (bastante propia) y, por último, Cataluña y Murcia con un 5 (muy propia).

La competencia C.3. (Dar a conocer los pasos o herramientas de los procesos en la propia práctica) le sigue en media a la anterior, en esta ocasión con un 4.2, considerándose dicha competencia como bastante propia del educador social. Castilla y León y Extremadura advierte que es poco propia de este profesional (3), Castilla-La Mancha, que sí que es bastante propia (4) y, para finalizar, Cataluña, Murcia y las Islas Baleares la estiman como muy propia (5).

Las competencias C.2. (Destreza para reconocer los contenidos culturales, lugares, individuos o grupos a poner en relación) y C.4. (Saber poner en relación los contenidos, individuos, colectivos e instituciones) obtienen la misma nota 
media: un 4.3. En la C.2., Castilla y León otorga un 3 (poco propia), seguido de Islas Baleares y Extremadura, con un 4 (bastante propia) y culminando con Castilla-La Mancha, Cataluña y Murcia con un 5 (muy propia). En la C.4. Extremadura es el que ofrece menor valor numérico, un 3 (poco propia), seguido de Castilla y León e Islas Baleares, con un 4 (bastante propia) y terminando con Castilla- La Mancha, Cataluña y Murcia, como en la competencia C.2., otorgando un 5 (muy propia).

En la Tabla siguiente (1) se engloban las respuestas de los colegiados y la media de cada competencia, que forma parte de la función mediadora, analizada en las líneas anteriores: 


\begin{tabular}{|l|l|l|l|l|l|l|l|}
\hline COMPETENCIAS & CEESCYL & CESCLM & CEESC & CPESRM & CEESIB & COPESEX & $\begin{array}{l}\text { MEDIA DE LA } \\
\text { COMPETENCIA }\end{array}$ \\
\hline $\begin{array}{l}\text { C.1. Conocimientos teóricos y } \\
\text { metodológicos sobre } \\
\text { mediación en sus diferentes } \\
\text { acepciones }\end{array}$ & 3 & 4 & 5 & 5 & 3 & 2 & 3.7 \\
\hline $\begin{array}{l}\text { C.2. Destreza para reconocer } \\
\text { los contenidos culturales, } \\
\text { lugares, individuos o grupos a } \\
\text { poner en relación }\end{array}$ & 3 & 5 & 5 & 5 & 4 & 4 & 4.3 \\
\hline $\begin{array}{l}\text { C.3. Dar a conocer los pasos o } \\
\text { herramientas de los procesos } \\
\text { en la propia práctica }\end{array}$ & 3 & 4 & 5 & 5 & 5 & 3 & 4.2 \\
\hline $\begin{array}{l}\text { C.4. Saber poner en relación } \\
\text { los contenidos, individuos, } \\
\text { colectivos e instituciones }\end{array}$ & 4 & 5 & 5 & 5 & 4 & 3 & 4.3 \\
\hline $\begin{array}{l}\text { MEDIA DEL } \\
\text { ENCUESTADO EN LAS } \\
\text { COMPETENCIAS }\end{array}$ & 3.2 & 4.5 & 5 & 5 & 4 & 3 & 4.1 \\
\hline
\end{tabular}

Tabla 1. Valoración de los colegiados en relación a la mediación social, cultural y educativa y las competencias que engloba. 



\section{Discusión y Conclusiones}

Retomando los objetivos que se establecieron en este trabajo, se podría decir, con respecto al primer de ellos planteado: "Identificar la importancia que ofrece la acción mediadora en el ámbito de las personas mayores" que la investigación pone de relieve la importancia del trabajo educativo desde la óptica de la mediación. Dicha función es atribuida al profesional de la Educación Social y se enmarca entre una de sus competencias, ya que debido a su formación está capacitado para ello.

Además de acuerdo con el segundo objetivo del trabajo: "Analizar las atribuciones y acciones profesionales desarrolladas por los educadores sociales" se ha podido comprobar que la mediación comprende varios significados y deriva en diversas acciones, no estando supeditada a una receta, ni siendo acontextual, sino englobando tantas formas como personas y escenarios. Desde una resolución de conflictos, una representación de un grupo poblacional, el poner voz a personas que no la tienen habitualmente, solventar el distanciamiento comunicativo entre generaciones, favorecer el desarrollo comunitario, la mejora de las relaciones familiares... y un largo etcétera.

Entre ellos podría destacarse de acuerdo con el trabajo de Rozenblum (2007: 15) que "el conflicto ocurre en todas partes. Si se lo maneja de modo efectivo, puede convertirse en una experiencia positiva de aprendizaje. Si se lo maneja de modo no efectivo, el conflicto puede transformarse en violencia física y emocional". En el colectivo de personas mayores que se enfrentan en esa etapa de sus vidas a diversos conflictos personales y sociales, el papel que puede ejercer la figura mediadora del educador social para sensibilizarlos y motivarlos a asumir una perspectiva positiva frente al conflicto pasa por entenderlo como una oportunidad para mejorar la convivencia, realizar aprendizajes sociales, aplicar la creatividad, debatir y conocer mejor a las personas implicadas. Habría que considerarlo, por tanto, un proceso de crecimiento personal y social. Algo esencial a combatir en este colectivo, que tradicionalmente ha estado expuesto a situaciones de infravaloración social cuando llegan a la etapa de la jubilación como refleja el trabajo de Martínez de Miguel, Escarbajal de Haro y Salmerón (2016).

Además, otro de los retos a trabajar en esa línea con el colectivo de mayores es el ámbito de las relaciones interpersonales. De acuerdo con el trabajo de Martínez de Miguel y Escarbajal Frutos (2009: 167): "el poder comunicarse e interactuar con los otros, de modo que puedan sentirse seguros y capaces de poder analizar sus circunstancias y contexto y comprometerse, de manera activa, en su propio desarrollo social y personal". Algo que se ha visto reflejado en muchas de las opiniones al respecto por parte de los profesionales y personas mayores participantes de esta investigación y que expresa claramente otra de las acciones profesionales a realizar por la figura del educador social.

Por lo que, en definitiva, se necesita de un profesional que tenga los conocimientos, recursos y técnicas necesarias para que una divergencia, un conflicto, unas opiniones dispares, la necesidad de hacer llegar voces, de ser escuchados... suponga una oportunidad y no un problema. Y es ahí donde el educador social, por su formación en el ámbito socioeducativo, a lo que se suman las demandas de un nuevo colectivo de personas mayores que presentan 
necesidades más allá de mero asistencialismo y/o paternalismo al que venían acostumbrándonos, siendo éstas cada vez más socioeducativas, donde el profesional de la Educación Social, en su faceta mediadora, cobra especial relevancia.

\section{Referencias bibliográficas}

Asociación Estatal de Educación Social. (2007): "Documentos Profesionalizadores". Disponible en http://www.eduso.net/archivo/docdow.php?id=143

Bermúdez, K., Prats, G. y Uribe, E. (2000): La mediación intercultural: un puente para el diálogo. Barcelona: Desenvolupament Comunitari. Ed.propia.

Cohen-Emérique, M. (1997): "La négotiation interculturelle phase esentielle de l'integration del migrants", Hommes \& Migrations, 1208, pp.9-23.

COIE (2017). Ficha de salidas profesionales de la Titulación de Educación Social. Recuperado de: $\mathrm{http}: / /$ salidasprofesionales.um.es/web/salidas/guia-salidas?area $=401$

Málik, B. y Herraz, M. (2005). Mediación Intercultural en contextos socioeducativos. Málaga: Ediciones Aljibe.

Martínez De Miguel, S. (2003). Reconstruyendo la Educación de Personas Mayores. Granada: Grupo Editorial Universitario.

MARTÍNEZ DE MIGUEL, S. y ESCARBAJAL FRUTOS, A. (2009): "La mediación intercultural dirigida a las personas mayores inmigrantes", Mediaciones Sociales. Revista de Ciencias Sociales y de la Comunicación, 4, pp.159-187.

Martínez De Miguel, S., Escarbajal De Haro, A. y Salmerón, J.A. (2016): “El planteamiento socioeducativo en el trabajo con personas mayores. El punto de vista de los profesionales", Revista Electrónica Interuniversitaria de Formación del Profesorado, vol.19, $\mathrm{n}^{\circ}$ 2, pp. 315-328. DOI: http://dx.doi.org/10.6018/reifop.19.2.202681

Múgica, J. (1991): Imagen del educador desde la Asociación Agintzari. Bilbao: Asociación de Educadores Especializados.

Pérez De Guzmán, M. V. (2008): "La mediación en los centros educativos. El educador social como mediador", Bordón, .60(4), pp.79-87.

Plannas, A, Pineda, P. y Gil, E. (2014). La metodología de la evaluación participativa de planes y acciones comunitarias. Tres experiencias de evaluación participativa en Catalunya. Pedagogía Social. Revista Interuniversitaria, 24, 105-134. http://dx.doi.org/ 10.7179/PSRI_2014.24.05.

Rozenblum, S. (2007): Mediación. Convivencia y resolución de conflictos en la comunidad. Barcelona: Editorial Graó.

Rueda, M. A. (2013): "Envejecimiento y mediación: nuevos cuidados, nuevos conflictos" Blog envejecimiento en red. Disponible en 
https:/envejecimientoenred.wordpress.com/2013/07/03/envejecimiento-y-mediacionnuevos-cuidados-nuevos-conflictos/

Sánchez, E. (2013): “La mediación como competencia profesional en Educación Social”. En M. T. Castilla, V. Martín, E. Vila y A. M. Sánchez (Eds.), Educación y cultura de paz en contextos educativos (pp.283-292). Granada: Editorial GEU. 